\title{
Cover characteristics of a large gold tailings storage facility in South Africa: a case study
}

\author{
SJ van Wyk Agreenco Environmental Projects, South Africa
}

\begin{abstract}
Topsoil placement on Tailings Storage Facilities (TSF's) is not considered as standard rehabilitation practice in South Africa (SA). Historically, final earth covers have not been prescribed as part of tailings design and operation and no topsoil has therefore been provided in any way, let alone the financial provision thereof. Since final closure is nearing many mining operations, social and regulatory pressure confront mine owners to the reality of the impacts of uncovered TSF's. Millions of people reside in urban areas where tailings facilities frequent the landscape (especially around Gauteng, Northwest and Mpumalanga Province). Environmental and geotechnical risk may also emanate from uncovered facilities where surface erosion, as well as water, soil and air pollution protection measures need to be committed to as part of final closure. From a lifecycle cost perspective, topsoil covers are now considered more readily as a viable closure solution alternative compared to liner and geo-membrane covers. However, limited knowledge exists about tailingssoil cover interactions, geotechnical implications of covers, and the eco-functional role thereof. The largest gold tailings facility in South Africa (>700ha) is coincidentally one of the exceptions since it is concurrently rehabilitated by means of topsoil on the side slopes and benches. This case study leads the way in understanding the performance of earth covers on SA gold TSF's and provides insights into the soil cover performance, which now date back more than 50 years. The aim of the study was to investigate uniformity of soil placement through soil texture, soil depth, soil and tailings moisture content, vegetation surface cover and species richness across the rehabilitated tailings landscape. From the findings it was clear that distance to topsoil source and ramp access characterised the type of soil placed on the side slopes. It was found that five different soil classes were placed across the facility. Soil depth varied across the landscape and shale and dolerite rock matrix were frequently found throughout the study area. Furthermore, soil moisture levels in the cover were found to correlate with soil texture especially on high clay soil cover percentage, whilst moisture in the tailings was consistently the same throughout, except below clay soil covers. From a vegetation perspective, the surface cover was still less than $60 \%$ and the TSF is still in a pioneer state with weeds dominating the species richness and mainly commercially seeded grass species still occur. Since no original cover design for functionality criteria was considered as part of the operational focus, this case study presents an opportunity for real time field laboratory feedback on various soil textural and moisture regimes, and the information can be considered in the future design of topsoil covers for tailings facilities, whilst learning more about the ecological response to cover characteristics and climatic variability. Information about the functioning of the store-and-release cover could also be generated and advise whether the closure objectives can be met or to advise on objectives. Furthermore, approach must be incorporated into realistic closure success analogues for rehabilitation performance assessment standards in South Africa and underline realistic closure outcomes and an understanding of the total cost of ownership of a long term TSF operation.
\end{abstract}

Keywords: topsoil cover, tailings storage facility, tailings moisture, soil cover depth

\section{$1 \quad$ Introduction}

Designing and operating tailings landscapes for closure has become integrally part of the tailings engineering thought process and design principles. Tailings structures need to stand the test of time against natural erosive forces and water erosion is usually well accounted for in closure design. One of the preferred ways in which the risks posed by tailings is mitigated after final construction and deposition is by covering the surface area of the TSF with purpose-designed vegetated soil/rock covers that function as the final protective measure against erosive forces and provide the foundation for the development of functional, sustainable 
ecosystems. This store-and-release cover serves to intercept incident precipitation, store infiltration within the cover and release it via evaporation and vegetative transpiration, thus minimising the oxygen and water ingress that can reach the underlying tailings. This must form the basis for predictive modelling scenarios and shape the cover functional requirements after closure whilst informing the daily management philosophy during operation. This approach of covering TSF's with these topsoil covers have been accepted in many parts of the world as best practice, especially for new projects, whilst in South Africa, final closure best practice is still largely a future consideration in the wake of uncertainty under ever-changing regulations and cost scenarios (South Africa. GNR 632; South Africa GNR 926; South African National Standard No. 10286).

Historically, the consideration of final cover options has not formed part of formal design practices or final closure risk assessment in South Africa and as in many other countries, long-term closure success has been mainly an afterthought. Environmental and geotechnical risk also emanates from uncovered facilities where surface erosion, as well as water, soil and air pollution protection measures need to be committed to as part of final closure. Since no cover options (topsoil) has been provided for during the construction and operational phases of tailings facility's lifespan, the resultant uncovered and unrehabilitated TSF's have become permanent sources of pollution and the combination of erosive forces of wind and water will compromise the integrity of the facilities after closure risking the environmental sustainability for future generations. These facilities should be urgently covered or removed as the bulk of the environmental liability created now reside with the state and externalised environmental costs have become the responsibility of taxpayers. Governance pressure is however mounting on mining companies to prove that mine residue facilities will be closed responsibly and that stable and ecologically acceptable landforms are created during the operational phase to achieve sustainable closure. Geotechnical, environmental and health risks must be managed according to locally and internationally accepted best practice rehabilitation guidelines backed by scientific information about cover performance and sustainability.

Since final earth cover placement considerations have not been part of the tailings operational culture, case studies of topsoil cover behaviour that should inform future tailings operation and rehabilitation design is limited. This case study therefore presents an opportunity for real time field laboratory feedback on various soil and ecological response feedback to be considered in the future design of topsoil covers for tailings facilities, whilst learning more about the ecological response to cover characteristics and climatic variability.

In designing future TSF's, engineers should respond to the increasingly complex questions of perceptive pressure around environmental health protection, reducing nuisance dust, containment of environmental contamination and protection of ecosystem services through the design of appropriate covers. Information presented in this study about the functioning of the de-facto store-and-release cover could advise expected cover design outcomes and advise what the closure objectives should be or how it can be adequately achieved.

\section{Problem statement and methodology}

Topsoil placement on Tailings Storage Facilities (TSF's) is not considered as standard rehabilitation practice in South Africa (SA). Since final closure is nearing many mining operations, social and regulatory pressure confront mine owners to the reality of the impacts of uncovered TSF's. From a lifecycle cost perspective, topsoil covers are now considered more readily as a viable closure solution alternative compared to liner and geo-membrane covers, but limited knowledge exists about tailings-soil cover interactions, geotechnical implications of covers, and the eco-functional role thereof.

The largest gold tailings facility in South Africa ( $>700 \mathrm{ha}$ ) is one of the exceptions since it is concurrently rehabilitated by means of topsoil on the side slopes and benches. This case study leads the way in understanding the performance of earth covers on SA gold TSF's and provide insights into the performance of the soil cover, which now date back more than 50 years.

The aim of the study was to investigate the characteristics of a soil cover through soil texture, soil depth, soil and tailings moisture content, vegetation surface cover and species richness across the rehabilitated tailings landscape. The outcome of this study may inform cover design decision support for tailings closure in SA. 


\subsection{Case study background}

The owner of the TSF, a gold tailings reprocessing company, has been undertaking concurrent rehabilitation since the inception of the TSF more than 50 years ago. A mixed soil and rock cover is placed on the operational Tailings Storage Facility (TSF) slopes as it undergoes continued upward expansion through the cyclone deposition methodology. Low-grade tailings are deposited at a rate of 2.5 million tonnes per month and rate varies between $4 \mathrm{~m}-8 \mathrm{~m}$ per annum. The TSF is currently $120 \mathrm{~m}$ in height of which the intermittent benches are $100 \mathrm{~m}$ in length and $20 \mathrm{~m}$ vertically - there are between 5 and 8 benches around the TSF. The study was born when the Engineer of Record has requested that the mine investigate the surface and subsurface moisture regime associated with the covers as high clay percentages in topsoil covers may be associated with poor tailings dry-out and may contribute to recently isolated incidences of slope wetness and seepage risk.

The TSF owner has enlisted Agreenco (employer of the author and team) to carry out systematic field surveys on all soil-covered side slopes of the TSF with the following objectives:

1. Delineate the soil moisture content in the tailings below the soil cover and within the soil cover.

2. Characterise the soil texture and measure cover depth across the TSF.

3. Characterise the vegetation cover associated with the soil and rock cover.

\subsection{Study approach}

The scope of this study was to assess soil moisture characteristics in-and-below the topsoil cover. It was requested that a structured, qualitative vegetation cover assessment be undertaken as well, to characterise the vegetation quality of the cover soils. A three-stage process was proposed as follows:

- Stage 1: Survey focus on the soil moisture regime and wetness below the soils.

- Stage 2: Traverse each bench and auger through the cover and into the underlying tailings.

- Stage 3: Focus on improving boundary delineations between soil types based on findings above.

\subsection{Site description}

The study area is depicted in Figure 1 . The TSF is located $1 \mathrm{~km}$ to the west of Tsakane township and $15 \mathrm{~km}$ to the south of Ekurhuleni in the East Rand of the Gauteng Province of South Africa. The study area is approximately $1.4 \mathrm{~km}$ east of Rietspruit River, situated between two tributaries of the River, and is mostly surrounded by agricultural land.

Climatewise, it is a summer rainfall region, with very dry and frosty winters. The mean annual precipitation ranges between 630 and $720 \mathrm{~mm}$. Theis area's overall mean annual temperature is $15^{\circ} \mathrm{C}$, indicating a transition between cool temperate and warm temperate climate. Summer temperatures frequently exceed $30^{\circ} \mathrm{C}$ whilst winter minimum temperatures are below $0^{\circ} \mathrm{C}$ at night. Frequent incidences of frost occur throughout winter.

The mean annual potential evaporation is $2118 \mathrm{~mm}$ and mean annual soil moisture stress of $75 \%$ (evaporative demand is more than double the soil moisture supply for $75 \%$ (in Days) (Rutherford and Mucina, 2006). It is expected that the soils in this area are dry most of the time. The rainfall and temperature ranged are depicted in Figure 2. A wetter and colder season preceded the study period.

The diversity of soils found around the study area are mostly red-yellow-brown apedal deep soils, melanic clays (dark brown) in the low-lying areas and shallow plinthic soils. The red and red-brown soils are from the dolomite and chert of the Malmani sub-group of the Transvaal Supergroup, the yellow-brown and plinthic soils are from the Karoo sandstone and the black and melanic soils are from the dolerite sill (Karoo dolerite). 


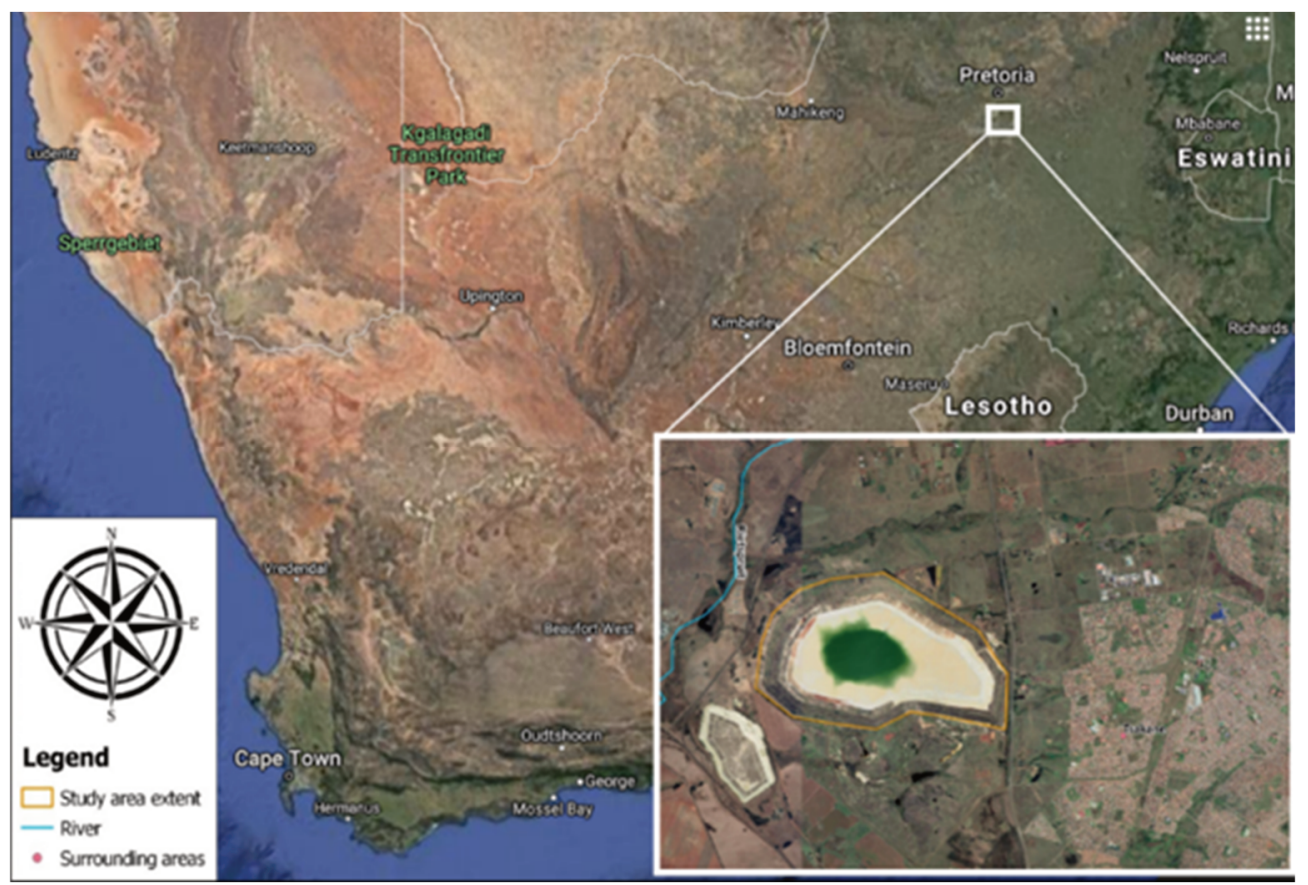

\section{Figure 1 Study Area Location}

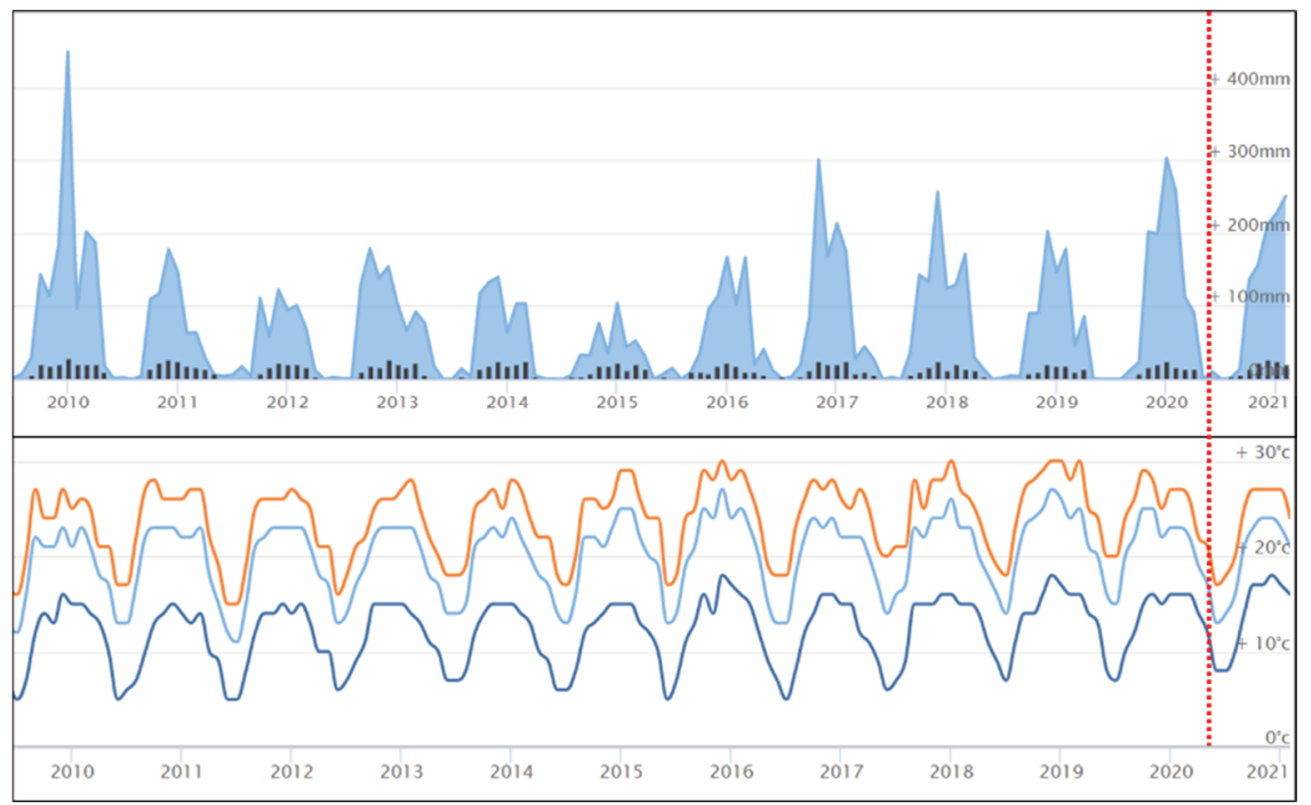

Figure 2 Rainfall and Temperature ranges from 2010 to 2020 for the East Rand of the Gauteng province of South Africa where the study site is located. The dotted line indicates the time of study (July 2020).

The slopes of the TSF were covered by mixtures of yellow brown apedal soils, melanic and black clays, and red and red brown apedal soils. The rocky material in the rock armour cover is mainly from the chert and dolerite borrow pits around the facility. Ecologically, the study area lies within the Tsakane Clay Grassland biome (Mucina and Rutherford, 2006) which is found on the ecotone between the Highveld Grassland and the Mpumalanga Moist Grassland around $1600 \mathrm{~m}$ a.s.l. The vegetation found in the Tsakane Clay Grassland biome typically short and dense grass swards, mostly dominated by a mixture of common highveld grasses. Grass species that commonly occur in this biome include Eragrostis species, Themeda triandra, Cynodon dactylon and Hyparrhenia hirta. The area is extensively grazed, and fire and animal trampling are major forces in this ecosystem's dynamics. 


\subsection{Study Methodology}

A three-stage approach was followed in conducting the assessments. The first stage involved focussing sampling on the southern aspect "wet" area, characterising the specific soils in the vicinity. Fifteen (15) sampling points were assessed within this area, with samples taken from 5 benches at 120-125 m intervals. The second stage entailed traversing each bench and collecting samples at $500 \mathrm{~m}$ lateral intervals. The third stage focused on improving soil boundary delineations on site by selectively sampling across the transition zones identified in stage 2 . This result in more accurate mapping and explanation of soil and vegetation characteristics.

Soil test pits were hand trenched with pick-and-shovel through the topsoil cover into the upper 100mm of the tailings material. A total of 116 sampling points were assessed across the tailings landscape (comprising of roughly $700 \mathrm{Ha}$ slope surface area, a $12000 \mathrm{~m}$ circumference, 5 benches across 8 lifts, and survey intervals of $500 \mathrm{~m}$ intervals along the mid slope contours).

The study did not incorporate any climatological data and was specifically conducted during the winter period when the season is cold and dry. The recent seasonal wetness and temperature may present some variance of future studies. The $2019 / 2020$ season was considered as above average moist and warm, and the winter conditions experienced were also more extreme than the previous 10 years before the study. More detail climatological information should however be incorporated into future studies to explain specific hydrological, or climate specific biophysical trends.

\subsubsection{Soil Assessments}

Soil assessments included measuring soil depth, rooting depth, visually assessing soil colour and texture, estimating rock content, and determining soil moisture content. A description of the soil assessment methods and importance of why it was measured is provided below.

\section{Soil Depth}

Soil depth is often defined as the maximum soil depth measured to the shallowest root-limiting layer, however, in this instance soil depth referred to the maximum thickness of the soil cover placed on the tailings layer. The mine aimed to place at least $300 \mathrm{~mm}$ of soil on all the slopes. Soil depth measurements were taken midway along the $20 \mathrm{~m}$ transect - picks and shovels were used to dig sufficient profile holes as the high rock content precluded the use of conventional manual soil augers.

\section{Soil texture}

Soil texture is the proportion of sand, silt and clay particles in a sample of soil. Texture has important effects on a wide variety of soil properties (e.g., soil's water holding capacity, aeration and porosity, hydraulic conductivity, compaction potential, resistance to root penetration, nutrient holding capacity (i.e., cation exchange capacity) and resistance to acidification (FAO-LADA 2011). In-field soil texture assessments were conducted using the methodology described by the Tongway and Hindley Soil Texture Flowchart (Tongway, 1970). The texture of the soils was confirmed by selecting 15 soil samples representing the different soils and submitting them for laboratory textural analysis (particle size distribution test).

\section{Soil Moisture}

Soil cover thickness influences the efficiency with which the tailings is insulated from moisture losses. Sandy soils have a rapid infiltration/evaporation rate but poor water retention capacity, whilst clayey soils have a slow infiltration rate but a positive water retention capacity. Soil moisture content was determined in the laboratory using the Gravimetric Method (Reynolds, 1970), which entails weighing the soils before and after oven drying. The tailings underlying the soils were also assessed for moisture and texture. Moisture differences were calculated. 


\subsubsection{Vegetation Assessments}

Soil cover thickness can also affect the types of plants that can grow on a rehabilitated area, especially when the soils are placed over tailings and with variation in cover depth, different vegetation assemblages may develop. This is due to topsoil or tailings material often having chemical properties that are growth limiting for most plants. Where tailings chemistry is growth limiting, only tolerant vegetation will survive, and succession processes and progress may take decades to initiate. A qualitative assessment of the vegetation cover was undertaken while traversing the benches. Assessments were performed along a $20 \mathrm{~m}$ gradsect, at $5 \mathrm{~m}$ intervals using a $1 \mathrm{~m}^{2}$ quadrat frame. The assessment entailed noting the species composition, dominant growth forms and overall cover (ground cover-canopy, rock and litter cover). The rationale was to delineate the spatial distributions of functional vegetation units and compare them to soil forms and moisture conditions. This was done to assist in evaluating whether the functional vegetation units express geotechnical risks or perhaps indicate areas of slope surface instability.

\subsubsection{Statistical evaluation}

To examine the existence and strengths of relationships between the measured soil cover variables and the underlying tailings moisture, we undertook a linear regression analysis. The analysis was performed on the data from soil cover type and depth, and the findings correlated with inherent soil moisture regimes compared to the soil moisture found in the underlying tailings material. The paired t-test function was applied to evaluate statistical differences related to soil moisture, depth and texture considering the mean characteristics' of the of the tailings material.

\section{Results and discussion}

\subsection{Soil and vegetation results}

From the study, five (5) main soil types were placed across the various slopes and benches of the study area. Figure 3 outline the soil texture results and Figure 4 present the soil depth findings.

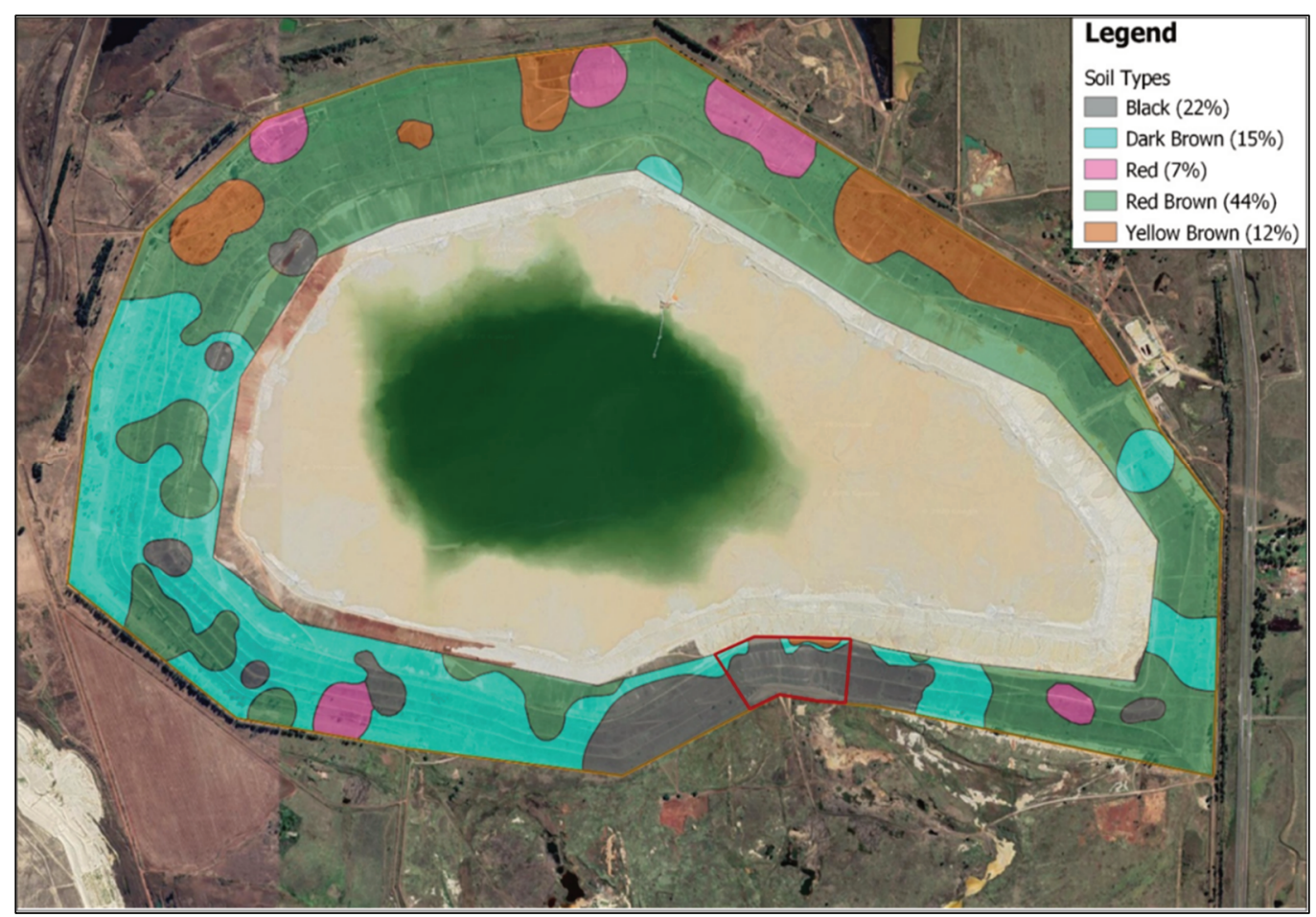

Figure 3 Soil Texture Results for the Study Site 
The technosols (disturbed, transported soils not placed in their natural sequence) soil colour was found to correlate with texture, moisture holding capacity and, to an extent, fertility and thus vegetation response. The integrated findings have been summarised in Table 1 for ease of reference and interpretation.

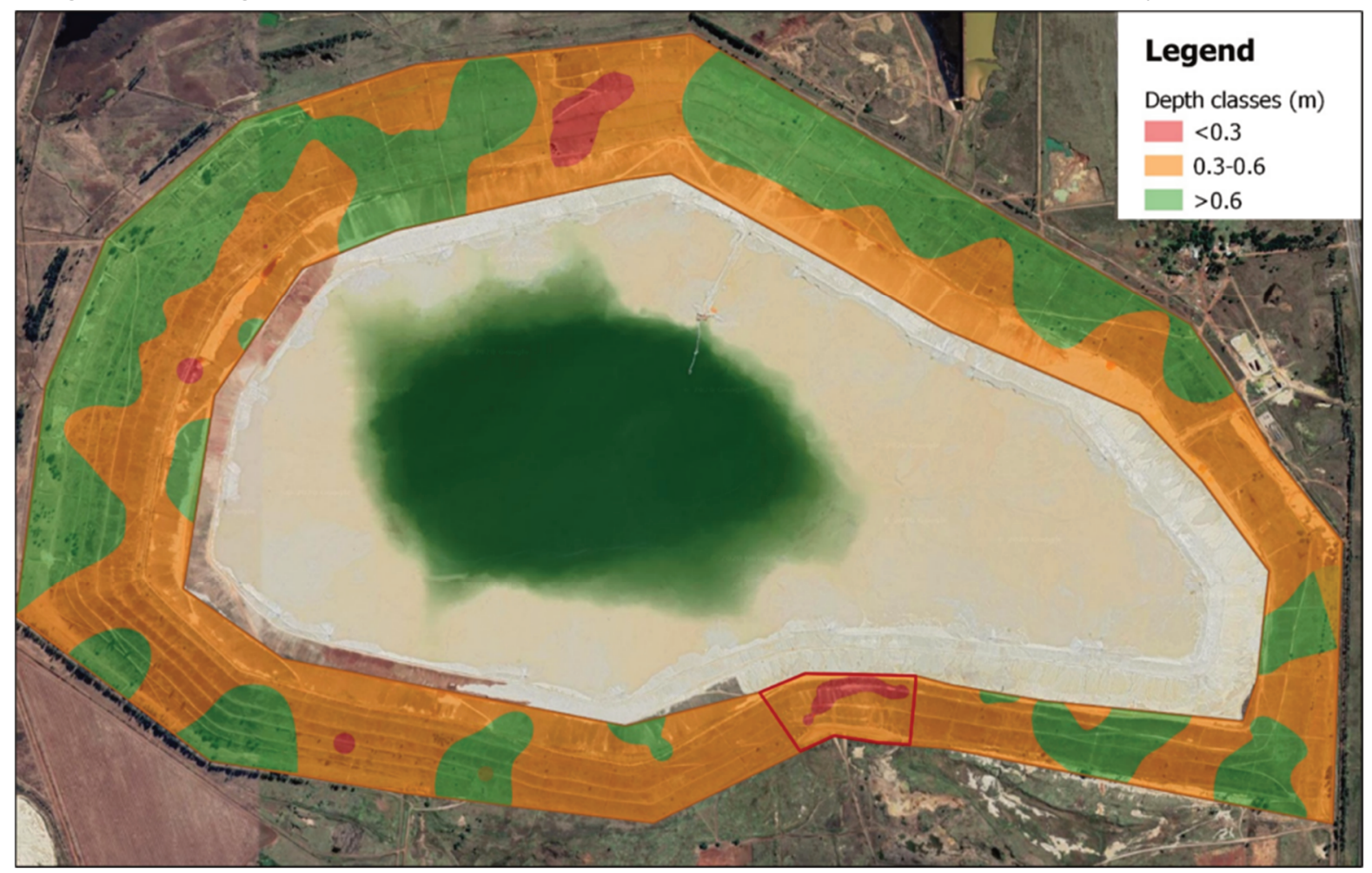

Figure 4 Soil Depth Results for the Study Site

Table 1 Summary of Soil and Vegetation Cover Characteristics of the studies TSF.

\begin{tabular}{|c|c|c|c|c|c|c|}
\hline & $\begin{array}{l}\text { Black } \\
\text { Saturated }\end{array}$ & Black & Dark Brown & Red & Red Brown & $\begin{array}{l}\text { Yellow } \\
\text { Brown }\end{array}$ \\
\hline $\begin{array}{l}\text { Soil Surface } \\
\text { cover } \\
\text { Extent (\%) }\end{array}$ & $8 \%$ & $14 \%$ & $15 \%$ & $7 \%$ & $44 \%$ & $12 \%$ \\
\hline $\begin{array}{l}\text { Dominant } \\
\text { texture: } \\
\text { Tongway \& } \\
\text { Hindley } \\
\text { (USDA) }\end{array}$ & $\begin{array}{l}\text { Clay (Sandy } \\
\text { clay loam) }\end{array}$ & $\begin{array}{l}\text { Clay (Sandy } \\
\text { clay loam) }\end{array}$ & $\begin{array}{l}\text { Sandy clay } \\
\text { (Sandy clay } \\
\text { loam) }\end{array}$ & $\begin{array}{l}\text { Loamy } \\
\text { sand } \\
\text { (Sandy } \\
\text { clay) }\end{array}$ & $\begin{array}{l}\text { Sandy clay } \\
\text { loam (sandy } \\
\text { loam) }\end{array}$ & $\begin{array}{l}\text { Loamy sand } \\
\text { (Sandy loam) }\end{array}$ \\
\hline $\begin{array}{l}\text { Average } \\
\text { Soil Depth } \\
\text { (m) }\end{array}$ & 0.34 & 0.48 & 0.67 & 0.57 & 0.56 & 0.59 \\
\hline $\begin{array}{l}\text { Average } \\
\text { Rooting } \\
\text { Depth (m) }\end{array}$ & 0.26 & 0.4 & 0.46 & 0.49 & 0.33 & 0.42 \\
\hline $\begin{array}{l}\text { Average } \\
\text { Soil } \\
\text { Moisture } \\
\text { content (\%) }\end{array}$ & 11.32 & 12.77 & 9 & 5 & 10 & 6 \\
\hline
\end{tabular}




\begin{tabular}{|c|c|c|c|c|c|c|}
\hline $\begin{array}{l}\text { Average } \\
\text { Tailings } \\
\text { Moisture } \\
\text { content (\%) }\end{array}$ & 12.48 & 6.25 & 5 & 4 & 7 & 6 \\
\hline $\begin{array}{l}\text { Species } \\
\text { richness }\end{array}$ & 7 & 4 & 29 & 13 & 32 & 20 \\
\hline $\begin{array}{l}\text { Average } \\
\text { Canopy } \\
\text { cover (\%) }\end{array}$ & 31.6 & 36.1 & 41.9 & 42 & 33.2 & 41.5 \\
\hline $\begin{array}{l}\text { Dominant } \\
\text { Species }\end{array}$ & $\begin{array}{l}\text { Chloris } \\
\text { gayana \& } \\
\text { Cynodon } \\
\text { dactylon }\end{array}$ & $\begin{array}{l}\text { Chloris } \\
\text { gayana \& } \\
\text { Cynodon } \\
\text { dactylon }\end{array}$ & $\begin{array}{l}\text { Cynodon } \\
\text { dactylon \& } \\
\text { Eragrostis } \\
\text { curvula }\end{array}$ & $\begin{array}{l}\text { Chloris } \\
\text { gayana \& } \\
\text { Cynodon } \\
\text { dactylon }\end{array}$ & $\begin{array}{l}\text { Cynodon } \\
\text { dactylon \& } \\
\text { Hyparrhenia } \\
\text { hirta }\end{array}$ & $\begin{array}{l}\text { Tagetes } \\
\text { minuta \& } \\
\text { Hyparrhenia } \\
\text { hirta }\end{array}$ \\
\hline
\end{tabular}

The soil forms at any given point on the cover were found to be composite mixtures of soil and rock with high variability on the various slopes. The following soil types were identified: Black soils, Dark brown soils, Red soils, Red-brown soils, Yellow-brown soils. All the cover material were found near the perimeter of the TSF from shallow quarries, and the colour of the soils also explained the source of soils.

The red-brown soils were the most prevalent. These soils are classified as Sandy Loam (USDA) and represented $44 \%$ of the sites assessed and were found across all aspects and specifically dominating on the northern and eastern portions of the TSF. The cover soils were moderately deep on average with acceptable, if shallow, rooting depths. Moisture content of the Red-brown soils was relatively high ( $9 \%$ vs. site average of 9.6\%) and varied considerably but was consistently higher than the underlying tailings. Species richness can also be classified as high, with Cynodon dactylon and Hyparrhenia hirta being the most dominant. The dominance of the former correlates well with past tailings spillages (supported by the evidence of high surface tailings cover over the topsoil where this species dominates).

The red soil covered $7 \%$ of the total surface area and is classified as loamy sand, mainly occurring in random patches on the bottom slopes of the TSF. The soil depth resembled that of the red-brown soils; however, the rooting depth was found to be shallower, which could be ascribed to lower soil moisture retention - evident from the soil moisture content data. Chloris gayana and Cynodon dactylon were the most dominant species recorded. Both species are stoloniferous grasses, which are ideal for slope stability and have high salt tolerance. However, during periods of prolonged drought conditions, Cynodon dactylon will become less functional (limited transpiration) and Chloris gayana will senesce due its low drought tolerance.

The yellow-brown soils were scattered almost randomly around the TSF and comprised numerous small pockets ( $12 \%$ total coverage). These soils are also characterised by a sandy loam texture, as are the redbrown soils. The high sand content and deep soils allowed for deep root penetration. The average soil moisture was relatively low and matched the underlying tailings moisture, although many cases did present with higher moisture in the cover than in the tailings. The Vegetation cover was high although the species composition was relatively poor, with a high prevalence of the annual weed, Tagetes minuta.

The black (22\%) and dark-brown soils (15\%) were also found to constitute large areas on the TSF. According to the USDA classification, both these soil types are classified as Sandy Clay Loam. On average, all the assessed parameters appear acceptable for the black soils, whilst that of the dark-brown soils was acceptable to good. The highest moisture content of samples collected in the black soil zone was $35 \%$ for tailings and $16 \%$ for soil, and only in this area did the tailings present higher moisture than the overlying cover soils. The black soils were found to be considerably shallower than the other soil forms. At the time of the survey (July-August, following a rainfall event), the grasses had been cut, which resulted in lower canopy cover values. Regarding the vegetation, species richness and species diversity. The rooting depth was satisfactory compared to the soil depth. Chloris gayana and Cynodon dactylon were the most dominant species recorded. 
The dark-brown soil comprised $15 \%$ of the total surface cover, total depth and rooting depth were deeper than the black soils. However, soil moisture was found to be lower. This may be attributed to the location of these soils relative to the black soils as well as the higher sand percentage compared to the black clays, 58and $49 \%$ respectively. For the dark-brown soils, the soil cover presented with higher moisture content than the underlying tailings. Cynodon dactylon and Eragrostis curvula were the most dominant species recorded on this soil type.

\subsection{Soil Moisture differential results and statistical evaluation of findings}

The relationship between moisture content and the different soils used as covers is indicative of the soil moisture regulation of the rehabilitated system and important aspect informing the eco-functional performance of the cover (The degree to which the cover either retains tailings moisture or functions as a true store-and-release cover). From the results it is evident that soil moisture varied according to the various soil types. It was also evident that except for the yellow-brown and red soil types, all the other samples presented higher moisture levels than the underlying tailings, except for a specific patch on the mid-southern slope covered with black soil - which presented higher tailings moisture than cover moisture.

Soil moisture results are presented in Figure 5, whilst the moisture differential between the soil cover and the tailings material is presented in Figure 6.

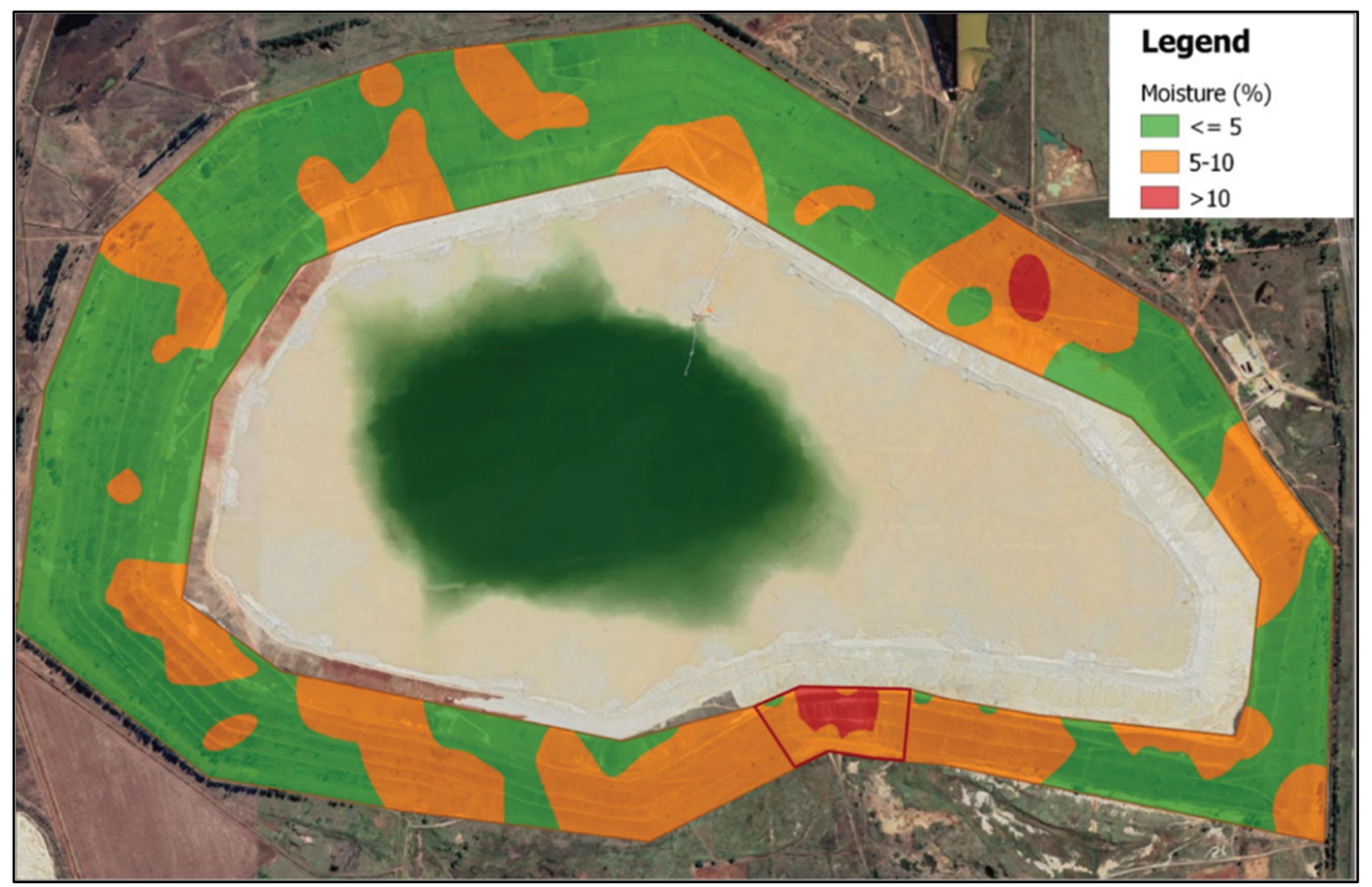

Figure 5 Soil Moisture Results for the Study Site

From the data it is evident that soil moisture in the topsoil cover were on average around $9 \%$ but the variance increased as ground level is approached. This could be explained by the natural downward movement of moisture through hydraulic head, although more in-depth studies need to explain the origin of the moisture - whether it is rainfall driven or driven through internal hydrological processes. The tailings moisture indicated roughly the same trend with average moisture content around $7 \%$ - the only exception around high variability found along lift 3 . More in-depth study is required to explain the movement of seasonal moisture through the cover into the tailings material, but the high-level data indicate that cover moisture was higher compared to tailings and is related to cover characteristics. Tailings moisture was rather constant - except in an isolated locality where black clay cover was found. 


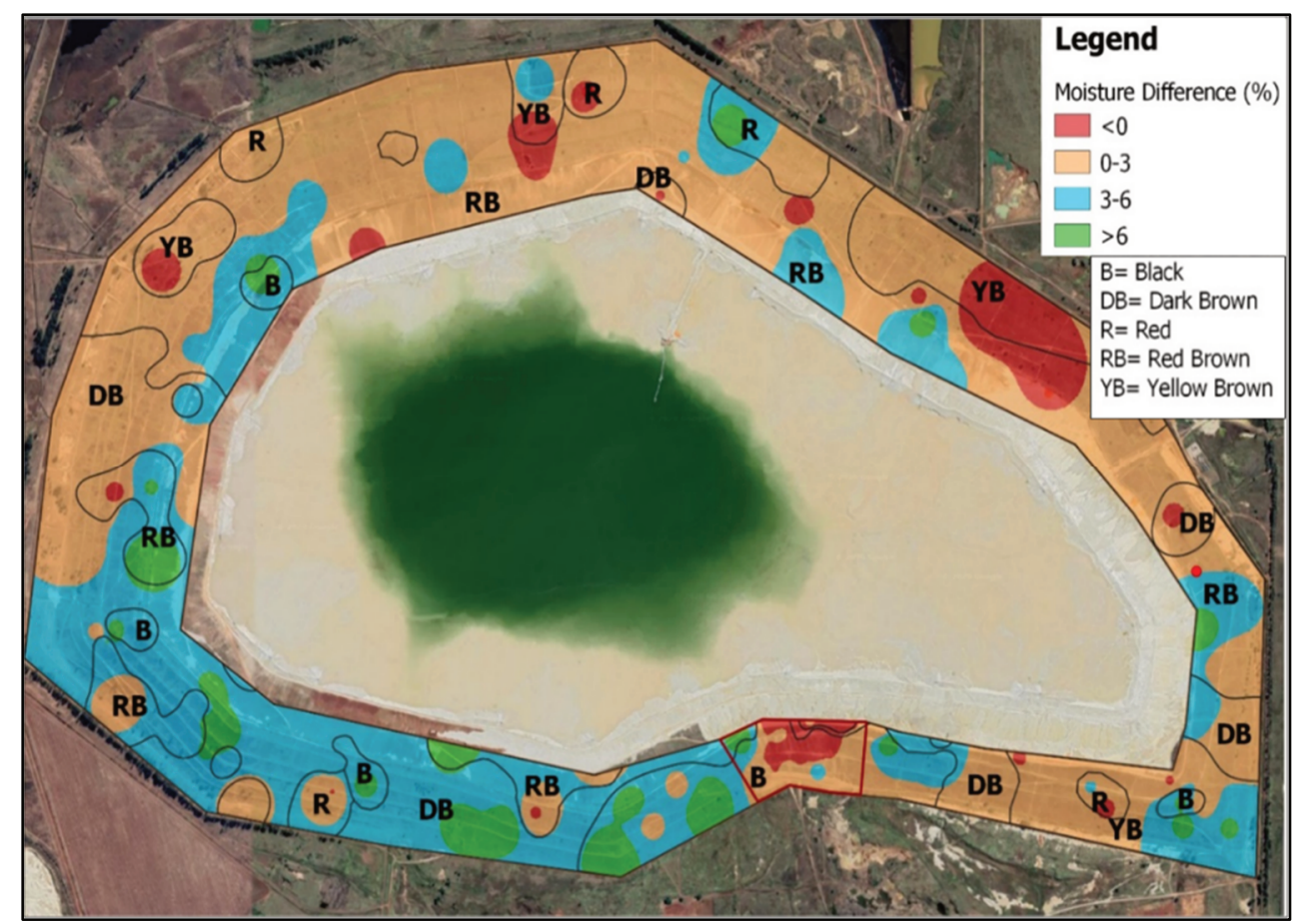

\section{Figure 6 Soil Moisture Differential Results for the Study Site}

The moisture differential data analyses showed that the moisture difference (soil moisture minus tailings moisture) of most of the sites varied between 0 and $6 \%$. This indicates that the cover soils are slightly moister compared to the underlying tailings. Conversely, there were also areas where the moisture content of the tailings was higher than that of the soil cover. These areas are located on Yellow-Brown and Black soils. The origins of this could be that the phreatic level of the dam is close to the surface, seepage is taking place and/or water is being discharged from the top of the $5^{\text {th }}$ bench on the southern aspect onto the surface. All of these factors have the potential to impact on the surface moisture of the sideslopes. The average soil moisture in the tailings and soil cover plotted across the vertical extent of the facility can give a high-level overview of moisture differential along the height of the facility on a lift or bench specific scale. The average soil moisture for the lifts is presented in Figure 7.

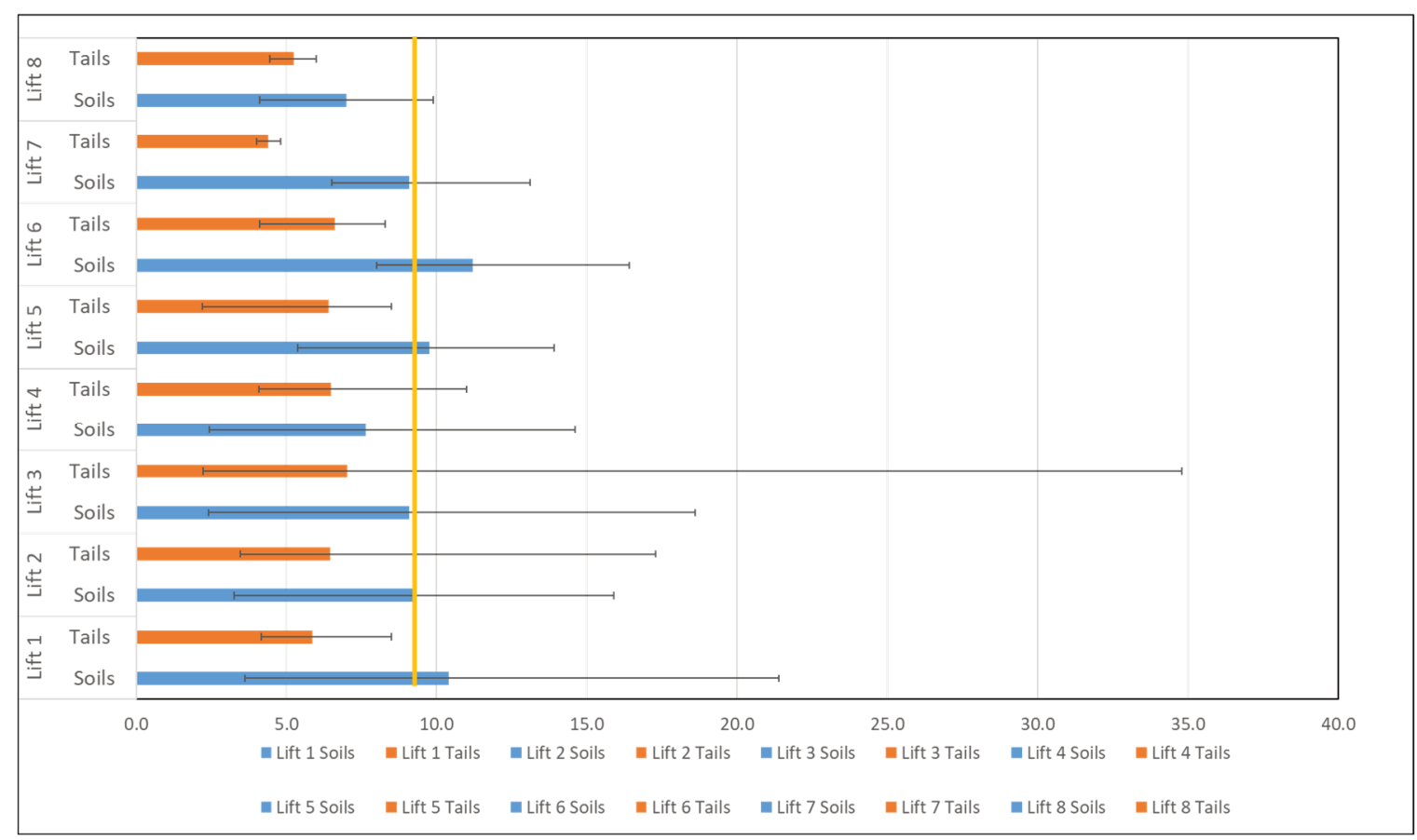

Figure 7 Soil moisture on plotted along vertical lift axis 
In order to examine the existence and strengths of relationships between the measured soil cover variables and the underlying tailings moisture, we undertook a series of linear regression analyses. The data is presented in Figure 8. for soil moisture content vs clay percentage and Figure 9 presents data for soil moisture vs soil depth. The linear regression for cover soil measure against clay percentage showed that the variance in the observed data was great and that no significant correlation could be found (Figure 8 ). $R^{2}$ values indicate that none of the soil cover trend lines satisfactorily explain the variation in the data, although the direction of the trendlines do suggest that there is a tendency for soil moisture to increase with increasing clay percentage, albeit statistically insignificant. The correlation coefficients for the regression were 0.15 (black soil), 0.30 (dark brown soil), 0.38 (red soil), 0.31 (red brown soil) and 0.65 (yellow-brown soil).

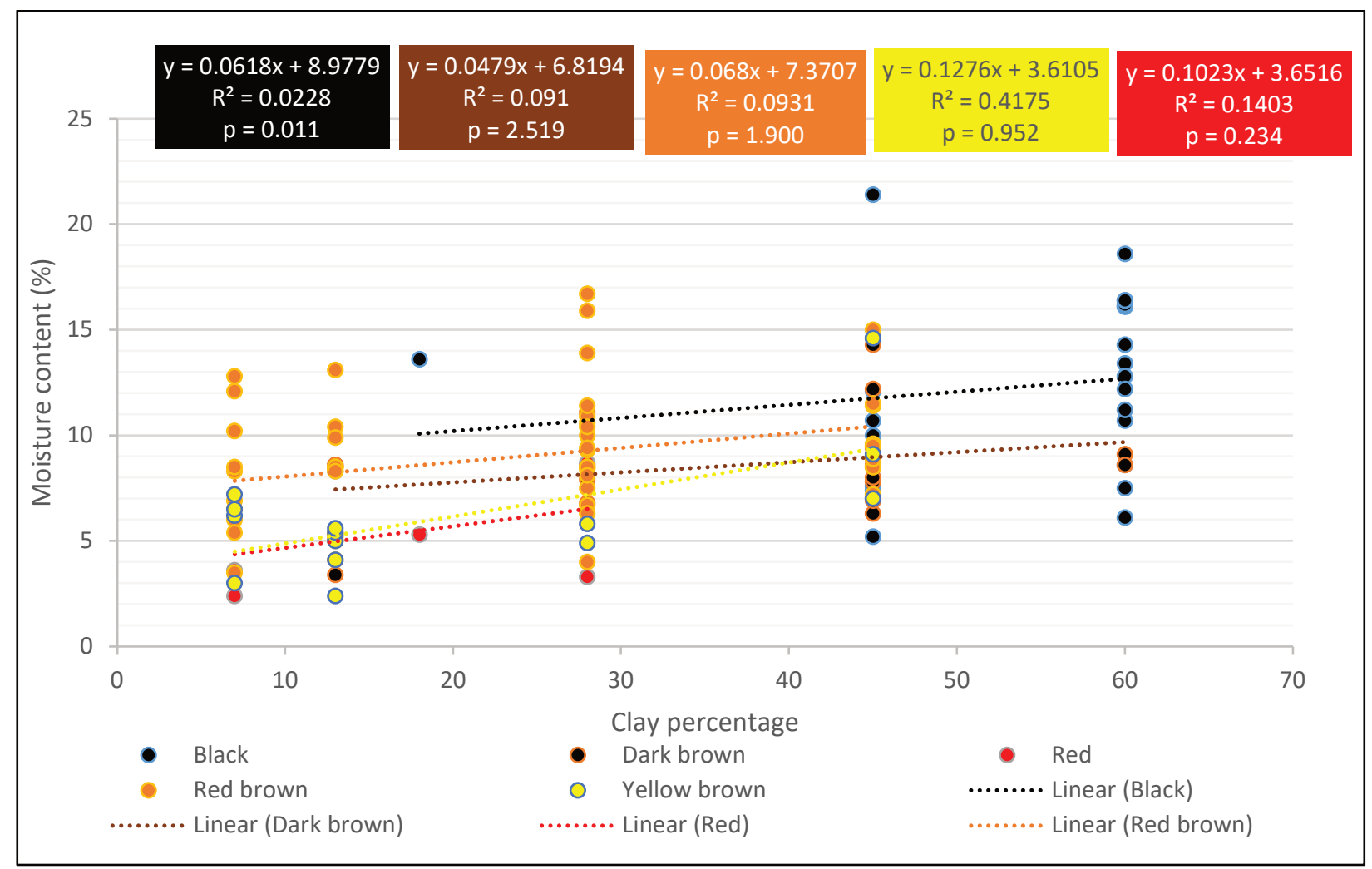

Figure 8 Linear Regression: Soil moisture vs clay percentage

From the the relationships between soil depth and soil moisture it was evident that the moisture varied with soil depth associated with soil form/texture, although the relationships were statistically insignificant (except for red soil which indicated a sound correlation between soil moisture and soil depth). The correlation coefficients for the regression were 0.11 (black soil), 0.15 (dark brown soil), 0.80 (red soil), -0.06 (red brown soil) and -0.15 (yellow-brown soil). 


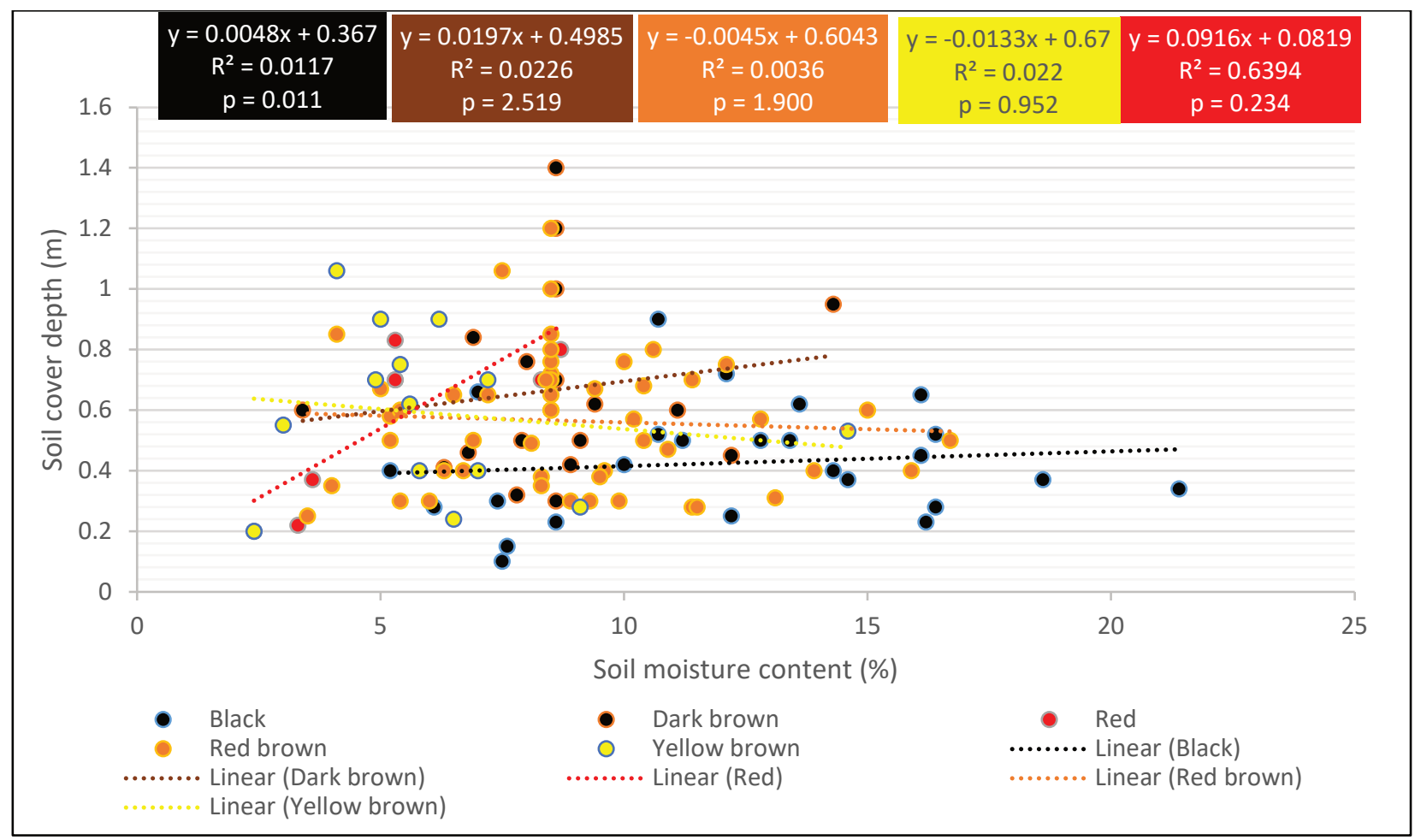

Figure 9 Linear Regression: Soil moisture vs soil depth on the TSF cover

- Yellow-brown soils presented lower soil moisture with shallower soil covers, as is expected from the higher sand percentage, and inferred high infiltration rates.

- Red soils presented increased moisture content with increasing soil depth.

- Dark brown, Black and Red-brown soil moisture did not indicate any correlation with soil depth.

Although the linear regression showed insignificant increases between clay percentage/soil texture and moisture content, the relationship between soil moisture recorded in the rock cover, as compared to the underlying tailings was investigated through paired t-test (considering the tailings moisture as median for the test). All the $p$-values were $>0.05$ (indicated as the $p$-values in Figure 8 and 9 above), explaining that high soil moisture did not correlate with high tailings moisture content - with the exception of a statistically significant relationship with black soils $(p=0.011)$ (Where the black soils are shallow and soil moisture is high, then the underlying tailings will have a correspondingly high soil moisture).

When isolating the moisture in the black soils and underlying tailings a further pattern emerges. The data presented in Figure 10 presents an overlay of soil moisture and soil depth and shows that most soil colours/textures have relatively deep soils, with correspondingly lower than average soil moisture compared to even lower tailings moisture content. This correlates with the statistical findings. However, considering the black soils only, soil moisture was found to be higher than the TSF cover average. The highest moisture was found on the southern slope, in some instances extremely so ( $35 \%$ tailings moisture). A contentious consideration is whether the high moisture can be explained by the soil cover in the area or by operational reasons such as concentrated water flow, seepage, or design oversight. 


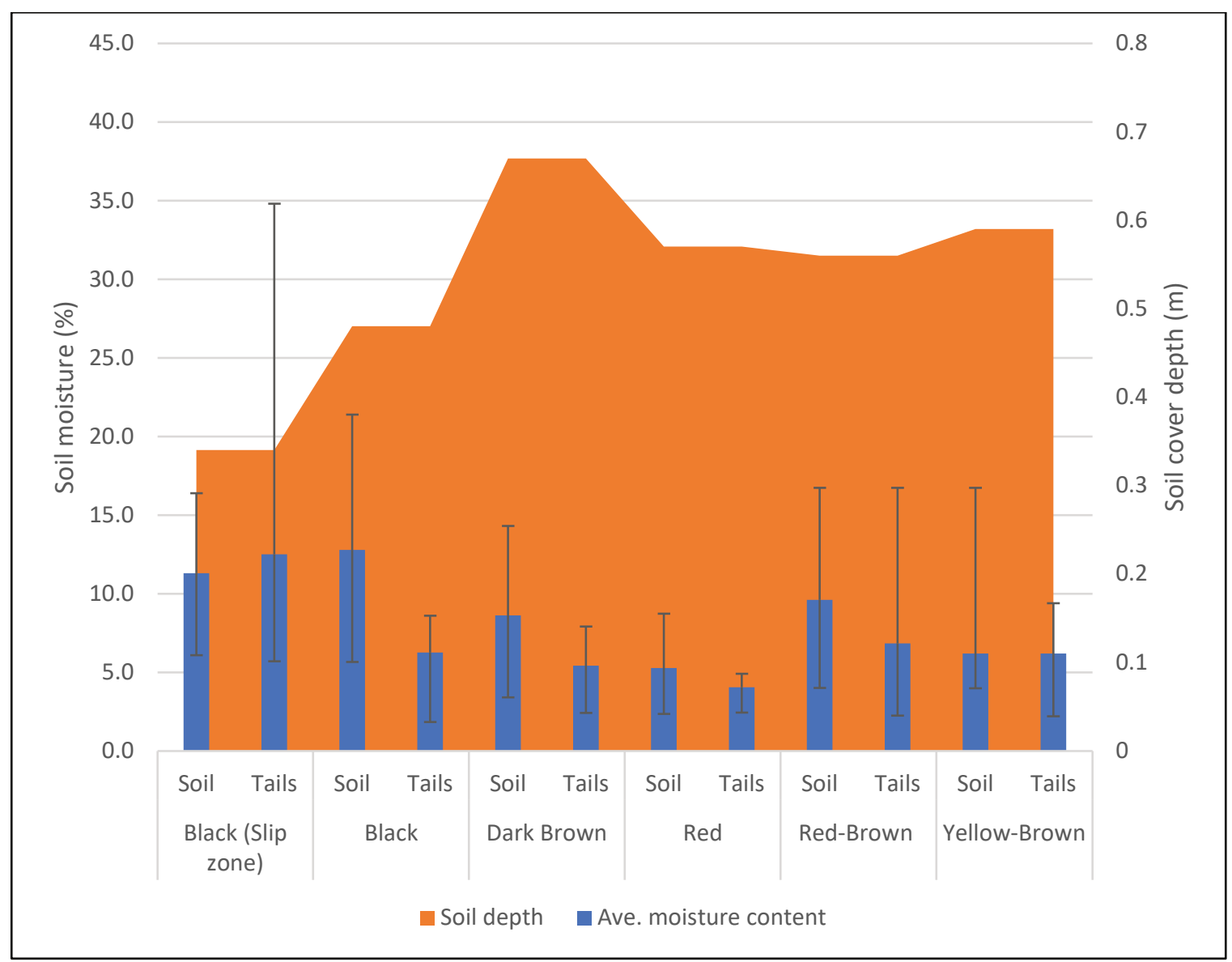

\section{Figure 10 Average moisture content of sampled soils and tailings}

\subsection{Vegetation Results: Vegetation units and Surface cover}

From the vegetation results, three distinct vegetation assemblages were identified which included Chloris gayana-Cynodon dactylon unit, Eragrostis curvula-Hyparrhenia hirta unit and Tagetus minuta-Hyparrhenia hirta unit. The vegetation assemblages did not resemble the surrounding natural vegetation which is dominated by Themeda triandra highveld grassland. Despite revegetation efforts of more than 50 years, the area is in mostly a pioneer state. The vegetation types are presented in Figure 11

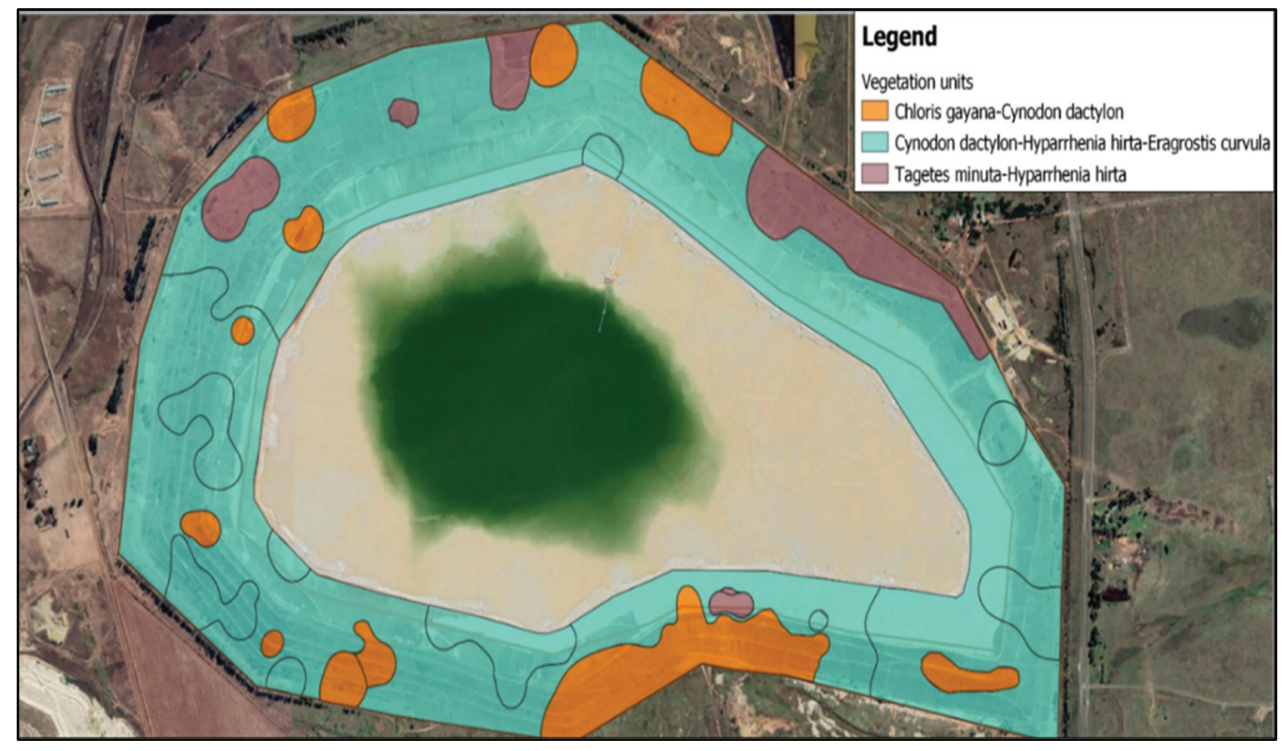

Figure 11 Vegetation Results for the Study Site 
Although species diversity was found to be surprisingly high, most of the vegetation cover can be regarded as weedy and disturbed-climax status. Considering the challenging environmental circumstances in which the vegetation layer must survive - which include high winds, wind chill cold conditions, high surface erosion pressure and poor soil nutrition, the system perform as best as it could.

Figure 12 outline the overlay of vegetation cover, soil type and soil moisture. Overall vegetation cover was similar for most of the soil types, with Red- and Dark-Brown soils having the highest cover. The vegetation assemblages were indicative of soil type and loosely correlated with topsoil moisture conditions.

The vegetation data showed a general trend that increased vegetation cover was associated with relatively lower soil moisture. The black soils, with highest soil moisture, thus showed the lowest vegetation cover. Although the yellow-brown soils had good vegetation cover, the species dominance was partly by weedy species. Therefore, the data suggests that the greatest vegetation cover is found where red and dark-brown soils are encountered. These are typically deeper soils on the TSF and have more balance loamy texture that, despite lower relative soil moisture, appear to support improved drainage and better edaphic conditions that the sand-dominated or clay-dominated soils.

The vegetation surface cover data and species richness summary are presented in Figure 13 . Less than $40 \%$ of the TSF is covered by vegetation canopy cover an although the rock cover and litter cover contribute to surface stability, the cover would be exposed to erosive processes. The species richness comprised of 45 species, mostly grass, and weedy alien invader plants. It is clear from the vertical average vegetation cover assessment that ground cover changed with rehabilitation age, i.e., the older the lift, the higher vegetation cover and the higher the species richness and composition. Repeat annual assessments of the vegetation data may provide insights into vegetation dynamics and ecosystem development.

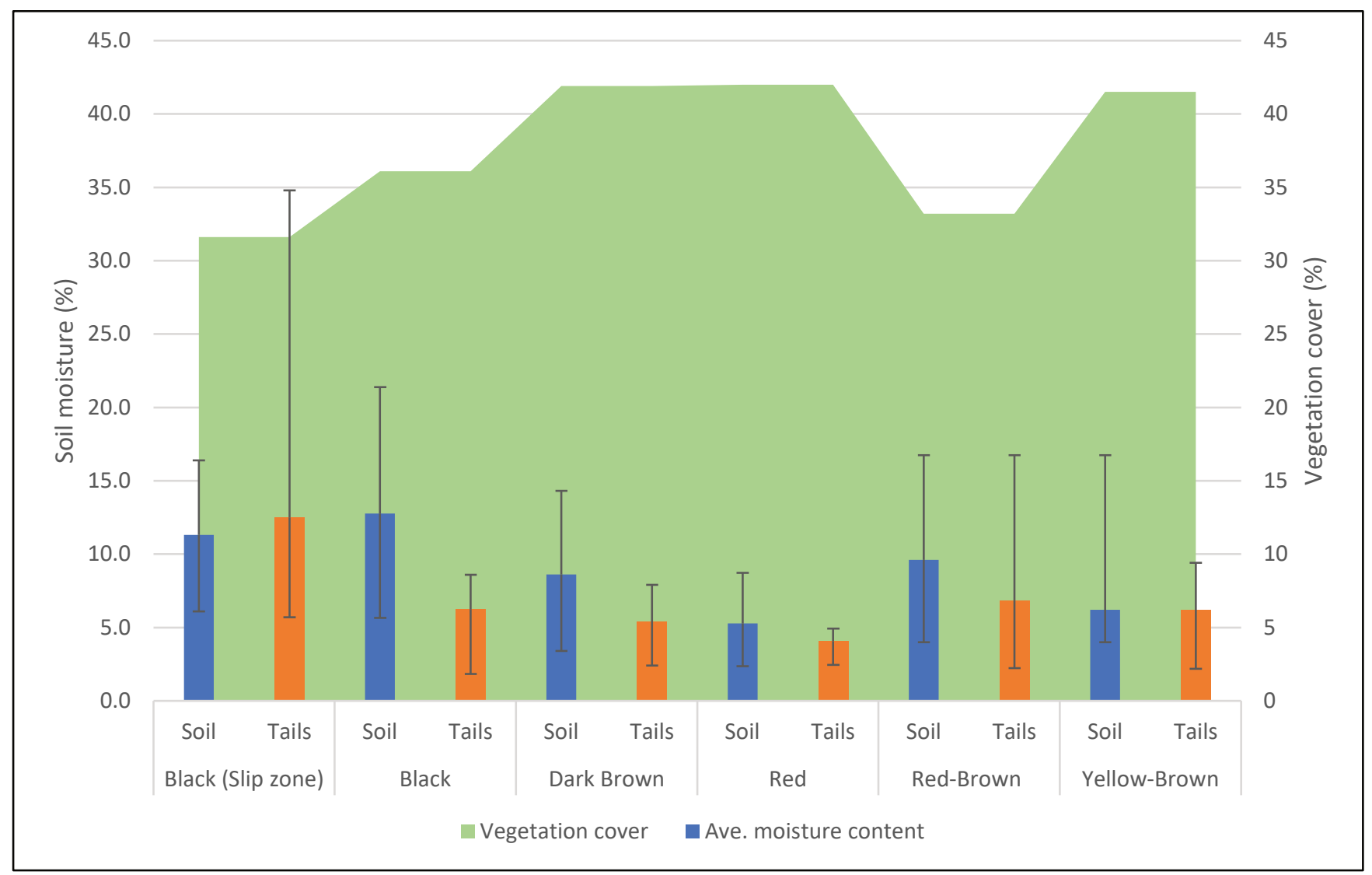

Figure 12 Average Moisture Content of Sampled Soils and Tailings per soil type location and associated vegetation cover. 


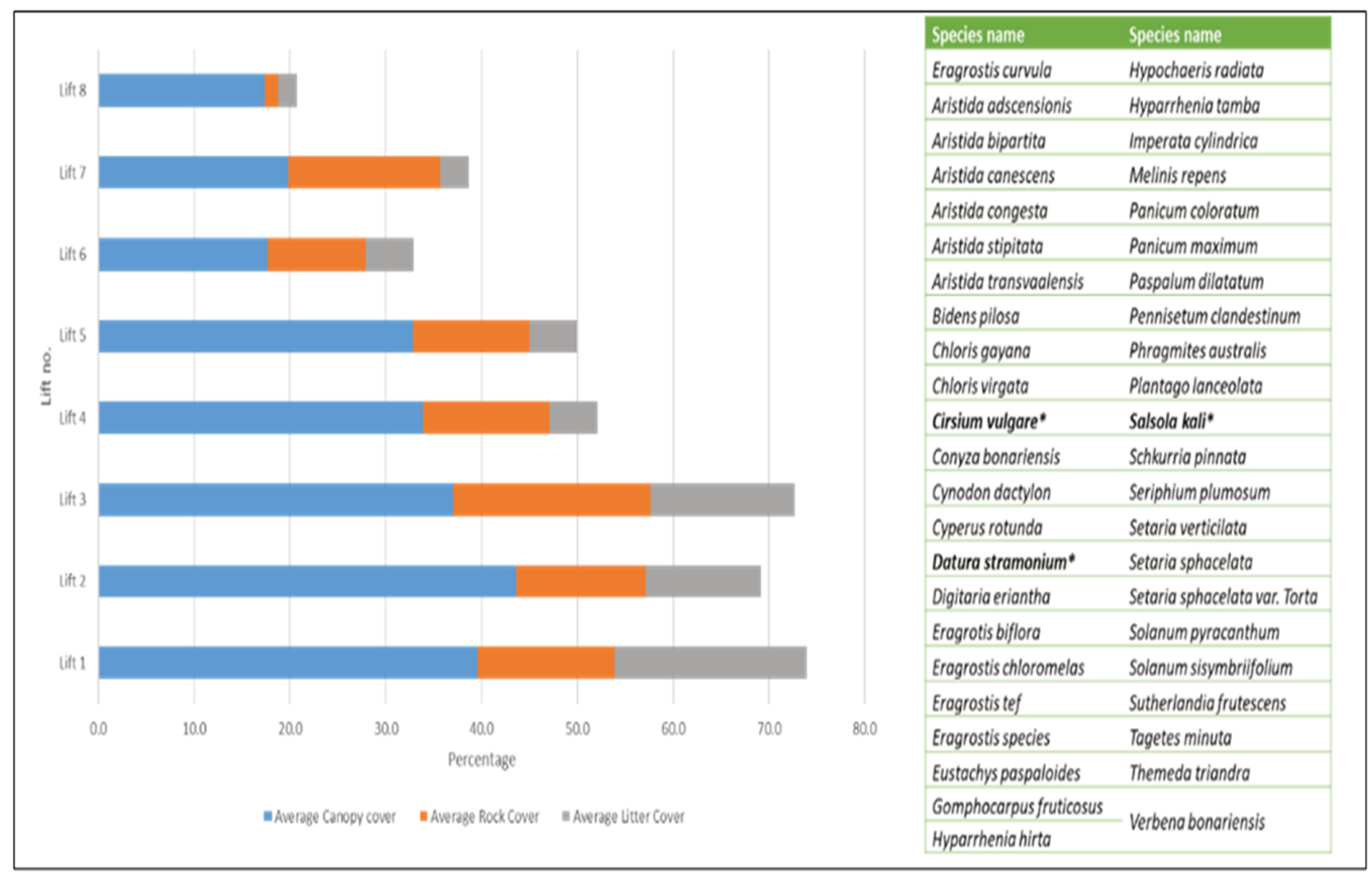

\section{Figure 13 Overall Vegetation Ground Cover Results and species list summary for the Study Site}

\section{Conclusion}

This case study provided valuable baseline information of the status quo functioning of a topsoil cover that is in progress for the past 50 years. The results from this study outline the importance to design the required outcome of a cover as the status quo approach presents no predictability in the behaviour of this cover and therefore no performance history would be available to the regulators for decision on final closure. The following summary on the key findings can be presented:

Topsoil characterisation for covers: The existing cover composes of 5 different soil types found closest to the TSF and is not placed according to any design specification or final closure objectives.

Topsoil placement and depth: Soil cover depth varied across the TSF, and depth did not consistently correlate with soil moisture although shallow black clay soil cover correlated with slightly higher moisture and elevated underlying tailings moisture.

Soil moisture regime: The surface moisture data in the various cover materials varied across the site, although linear regression analyses showed no significant relationship between clay percentage and soil cover moisture for the different soil types per se. There was a statistically significant relationship between cover soil moisture and the underlying tailings soil moisture for the black soils, which was insignificant for other soil forms. To establish moisture sources, detailed ongoing moisture probe studies would be required.

Vegetation performance: The area is in mostly an early pioneer ecosystem state and although species diversity was found to be relatively high, most of the vegetation cover can be regarded as weeds. Overall vegetation cover was similar for most of the soil types, with Red-and Dark-Brown soils having the highest cover. The relationship between vegetation cover and soil moisture was inconsistent. It was clear that species richness, species composition changed with rehabilitation age, i.e., the older the lift, the higher the species richness and composition. The vegetation assemblages were indicative of soil type and loosely 
correlated with topsoil moisture conditions. Vegetation cover (canopy and contact) correlated with the age profile of the topsoil placement on the TSF. Considering the current management approach, the system performs under the stress brough about by challenging environmental circumstances including high winds, episodic wind-chill conditions, temperature extremes and high surface erosion pressure.

Considering the results from this study, it is evident that in the interest of sustainability and long-term cost management, tailings decision makers should incorporate a pro-actively engineered eco-landscapes as part of the final closure design. By considering the design principles of "store-and-release" systems, tailings professionals should consider a different approach to achieve rehabilitated systems in equilibrium with the forces of the natural environment. Through frequently evaluation of the dynamics of rehabilitation performance criteria over time, soil and vegetation performance trends can act as early warning indicators or provide final success data that can underwrite the mine's application for closure and final relinquishment by regulators.

The ongoing monitoring trends must become part of tailings operational management and can be incorporated into realistic site-specific closure success analogues. This would lay the foundation for rehabilitation performance assessment standards in South Africa and underline realistic closure outcomes and an understanding of the total cost of ownership of a long term TSF operation.

\section{Acknowledgement}

We would like to acknowledge Agreenco for giving us the opportunity to present this information. I would also want to thank the owner of the mine for the opportunity to have done this valuable work.

\section{References}

Reynolds, SG 1970, 'The gravimetric method of soil moisture determination part 1: A study of equipment, and methodological problems'. Journal of Hydrology, vol. 11. pp. 258-273.

Rutherford, M, \& Mucina, L 2006, The vegetation of South Africa, Lesotho and Swaziland. in Strelitzia 19. South African National Biodiversity Institute, Pretoria

South Africa 1998, GNR 632: Planning \& Management of Residue Stockpiles. National Environmental Management Water Act.

South Africa 1998, GNR 926: National Norms and Standards for the Storage of Waste. National Environmental Management Water Act.

South Africa 2006, South African National Standard No. 10286. Code of practice of Mine Residue Facilities. Minerals and Petroleum Resources Development Act. Government Printer.

Tongway, DJ \& Hindley, NL 2004. Landscape Function Analysis: Procedures for Monitoring and Assessing Landscapes with Special Reference to Mine sites and Rangelands. CSIRO Australia. 